\title{
Influence of notch sensitivity and crack initiation site on low cycle fatigue life of notched components under multiaxial non-proportional loading
}

\author{
Stefano Bressan \\ Graduate School of Science and Engineering, Ritsumeikan University, 1-1-1, Nojihigashi, Kusatsu-shi, Shiga, 525-8577, Japan \\ gr0300kf@ed.ritsumei.ac.jp
}

Fumio Ogawa, Takamoto Itoh

Department of Mechanical Engineering, College of Science and Engineering, Ritsumeikan University, 1-1-1, Nojibigashi, Kusatsushi, Shiga, 525-8577, Japan

itobtaka@fc.ritsumei.ac.jpyahoo.com,ogawa-@@fc.ritsumei.ac.jpyahoo.com

\section{Filippo Berto}

Department of Mechanical and Industrial Engineering, Norwegian University of Science and Technology (NTNU), Richard Birkelands vei 2b, 7491, Trondheim, Norway

filippo.berto@ntnu.no

\begin{abstract}
A series of strain controlled multiaxial low cycle fatigue (LCF) tests under proportional and non-proportional loading conditions have been conducted on notched specimens. Cylindrical bars of $\mathrm{Al} 6061$ aluminum alloy and AISI 316L stainless steel with four values of stress concentration factors referred to the net section $K_{\mathrm{t}, \mathrm{n}}$ were employed. The experimental results evidenced a reduction of fatigue life due to non-proportional loading. Furthermore, the crack initiation site has been detected to be moved from the notch tip in the case of steel for high values of notch radius under nonproportional loading. Stress concentration factor evaluated in the elastic field $K_{\mathrm{t}, \mathrm{n}}$ has been included in the Itoh-Sakane parameter to evaluate the fatigue life, returning a general underestimation of fatigue life especially for high values of $K_{\mathrm{t}, \mathrm{n}}$. Material notch sensitivity and crack initiation position have been taken into account to further modify the model, improving the original results and showing a better assessment.
\end{abstract}

KEYwORDS. Non-proportional loading; Notch; Multiaxial loading; Low cycle fatigue; Crack initiation.

\section{OPEN ACCESS}

Citation: Bressan, S., Ogawa, F., Takamoto, I., Berto, F., Influence of notch sensitivity and crack initiation site on low cycle fatigue life of notched components under multiaxial nonproportional loading, Frattura ed Integrità Strutturale, xx (2019) ww-zz.

Received: 11.11 .2018

Accepted: 24.11.2018

Published: 01.01.2019

Copyright: (C) 2019 This is an open access article under the terms of the CC-BY 4.0, which permits unrestricted use, distribution, and reproduction in any medium, provided the original author and source are credited. 


\section{INTRODUCTION}

$\mathrm{M}$

any industrial applications require notched components to undergo non-proportional multiaxial low cycle fatigue. A suitable example of applications are parts of fast breeder reactors or aero engines. In terms of evaluation of fatigue life under multiaxial loading, a wide variety of methodologies have been developed. Stress based models [1-3] evaluate fatigue life through an equivalent stress parameter obtained from the stress components of the loading cycle. The field of applicability adapt to this typology of methods is the high cycle fatigue. Strain based models are instead typically associated with low cycle fatigue where significant plasticity may occur. Remarkable contributions for the evaluation of low cycle fatigue life were given by Brown-Miller [4], Fatemi-Socie [5] and Smith-Watson-Topper [6] whose models are based on critical plane, a surface which experiences the highest level of damaging over the cycle. Critical plane approaches are well known to estimate accurately the number of cycles to failure, although the detection of such plane might be time taking and the parameters associated with the model can be complex to obtain. Energy based models [7] are also applicable to low cycle fatigue loading cases.

Non-proportional loading is defined as the condition characterized by the variation of the first principal stress direction over the cycle. As a consequence, the number of activated slip bands in the material increases, causing additional hardening and a reduction of fatigue life, as evidenced in several works [8-17]. The mechanical phenomena caused by non-proportional loading often complicate the evaluation of fatigue life.

In actual applications, components feature geometrical discontinuities represented by notches, grooves and holes that provoke stress concentration phenomena. Stress concentration factor referred to the net section evaluated in static field $K_{\mathrm{t}, \mathrm{n}}$ does not describe accurately the reduction of fatigue life, often returning an underestimation of fatigue life. For this purpose, the fatigue notch factor $K_{\mathrm{f}}$ is usually employed. The most commonly accepted definition of the fatigue notch factor $K_{\mathrm{f}}$ is the ratio of the fatigue strength of a smooth specimen to that of a notched specimen, under the same experimental conditions and the same number of cycles. Although the most reliable method to determine $K_{\mathrm{f}}$ is through experimental data, $K_{\mathrm{f}}$ can be also evaluated by means of equations correlating this parameter with the original static elastic stress concentration factor and the notch sensitivity of the material [18-23]. In low cycle fatigue, stress and strain concentration factors evaluated in the plastic field $K_{\sigma}$ and $K_{\varepsilon}$ must be considered. Neuber [19] and Glinka [24] developed criterions to evaluate the local values of stress and strain in plastic field. It is worthy of note that Neuber's rule tends to overestimate the strain concentration factor. Several methodologies for the evaluation of the local values of strain and stress for non-proportional loading at the notch tip are reported in previous researches [25-28]. Some works demonstrated also that energetic approaches such as the evaluation of the average strain energy over a control volume around the notch [29-32] can be applied both for static and multiaxial fatigue field [33-37]. Recent and past suggested that the key for a correct evaluation of fatigue life are the strain and stress gradients in the proximity of the notch [38-39].

Several works on non-proportional multiaxial low cycle fatigue and researches on notches are well reported in the literature. The data on multiaxial fatigue on notched components is also present in the literature but it is mostly limited to tests in the high cycle fatigue environment [40,41].

Itoh and Sakane proposed a model specifically for low cycle fatigue and non-proportional loading [42,43]. Additional hardening $\alpha$ and severity of the loading path $f_{\mathrm{NP}}$ modify the first principal strain range to consider the non-proportionality of the applied loading cycle. The model has been applied for several materials, returning satisfying results [44]. Although non-proportional loading involves several complexities, the low number of required parameters makes this model simple to apply compared to the methodologies introduced above. However, time variable load amplitude and phase difference are not taken into account in this method, restricting its field of application to simple loading paths. In order to verify the validity of the model, hollow specimens have been originally tested, while notched specimens have been investigated only recently in a fewer number of papers. Sakane et al. [45] analyzed accurately notched specimens of AISI 304, evaluating the variation of number of cycles to initiation, propagation and failure depending on the value of $K_{\mathrm{t}, \mathrm{n}}$. Fatigue life was then correlated to the Itoh-Sakane parameter. AISI 316L notched specimens have been tested with non-proportional loading in a previous research $[46,47]$. The hardness of the specimens was firstly measured, and the fatigue life was estimated by using a modified Itoh-Sakane parameter. In detail, the authors applied the stress concentration factor evaluated in the elastic field. The results were in good agreement with experimental tests. On those specimens, the crack initiation site was found to be shifted from the notch tip. The maximum distance was observed for low values of $K_{\mathrm{t}, \mathrm{n}}$. From a FEM analysis that replicated the hardened areas around the notch tip, the cause of the shifted crack initiation position was found to be related to the strain gradient around the tip. The intensity of the gradient depended on the level of additional hardening and value of stress concentration factor. The originally evaluated fatigue life was improved by taking into account this phenomenon. In the literature, experimental data regarding this aspect are absent, making it necessary to test notched specimens made by materials with a lower level of additional hardening and lower notch sensitivity. 
The aim of this study is to verify the influence of notch sensitivity and crack initiation site on non-proportional low cycle fatigue life. To achieve this purpose, strain controlled multiaxial low cycle fatigue tests under proportional and nonproportional conditions on materials with different notch sensitivity and additional hardening have been conducted. Circumferentially notched bars made by Al 6061 aluminum alloy and AISI 316L stainless steel has been employed. Experimental tests have been performed to quantify the reduction of fatigue life induced by the non-proportionality of the loading path. The crack initiation site has been observed on the notch surface both on steel and aluminum. Fatigue data have been firstly synthesized with the Itoh-Sakane parameter modified with $K_{\mathrm{t}, \mathrm{n}}$. The static stress concentration factor evaluated in the elastic field have been replaced successively with $K_{\mathrm{f}}$. Finally, the effect of the crack initiation site has been taken into account through a parameter called $K_{\mathrm{t}}^{\prime}$. Evaluation of fatigue life employing the Itoh-Sakane parameter and crack initiation site are discussed throughout this study.

\section{MATERIALS AND TEST PROCEDURE}

\section{Material properties}

luminum alloy $\mathrm{Al} 6061(6061 \mathrm{Al})$ and austenitic stainless steel AISI 316L (316LSS) are the materials used in this study. Static mechanical properties are listed in Tab. 1.

\begin{tabular}{ccccc}
\hline Material & $\sigma_{\mathrm{Y} 0.2}$ & $E$ & $\varepsilon_{\mathrm{U}}$ & $\sigma_{\mathrm{U}}$ \\
& $\mathrm{MPa}$ & $\mathrm{GPa}$ & $\%$ & $\mathrm{MPa}$ \\
6061Al & 143 & 72.2 & 23 & 311 \\
316LSS & 356 & 178 & 55 & 518 \\
\hline
\end{tabular}

Table 1: Material mechanical properties.

The results of a standard tensile test evidenced the superior mechanical properties of the steel compared to aluminum. However, the material cyclic curves obtained through a cyclic plastic deformation under proportional and non-proportional loading have been indispensable to describe the material behavior in the field of low cycle fatigue. Proportional loading is represented by a push-pull (PP) loading path while non-proportional loading is represented by a circle loading path (CI). The loading paths are shown in Fig. 1.

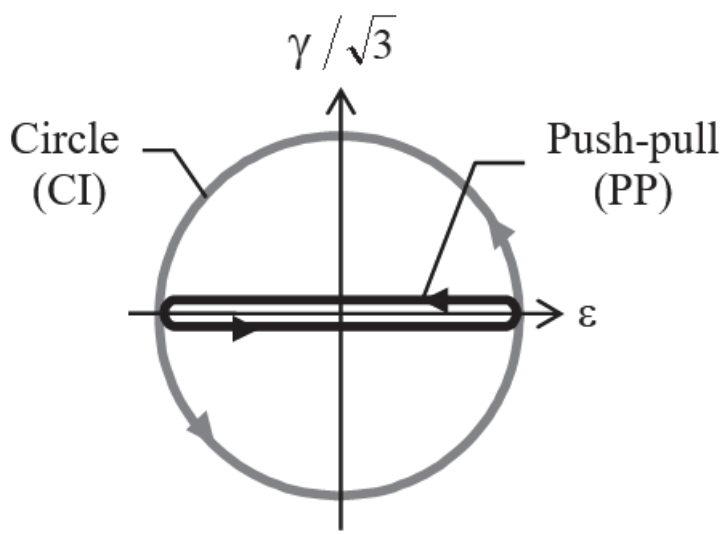

Figure 1: Applied strain paths.

Cyclic stress-strain curves associated with proportional and non-proportional loading have been obtained by a step-up test [48]. Strain increment at each step was set at $\Delta \varepsilon_{\text {eq }} / 2=0.05 \%$ every 10 cycles from $\Delta \varepsilon_{\text {eq }} / 2=0 \%$ to $\Delta \varepsilon_{\text {eq }} / 2=1.0 \%$. The dots constituting the curves shown in Fig. 2 represent the stress and strain amplitude values at the 10 assuming that the cyclic behavior of both steel and aluminum is stabilized. The cyclic curves of 6061Al and 316LSS in CI 
are characterized by higher levels of stress compared to those in PP. The discrepancy between the curves is due to the additional hardening effect, occurring when a non-proportional loading is applied.

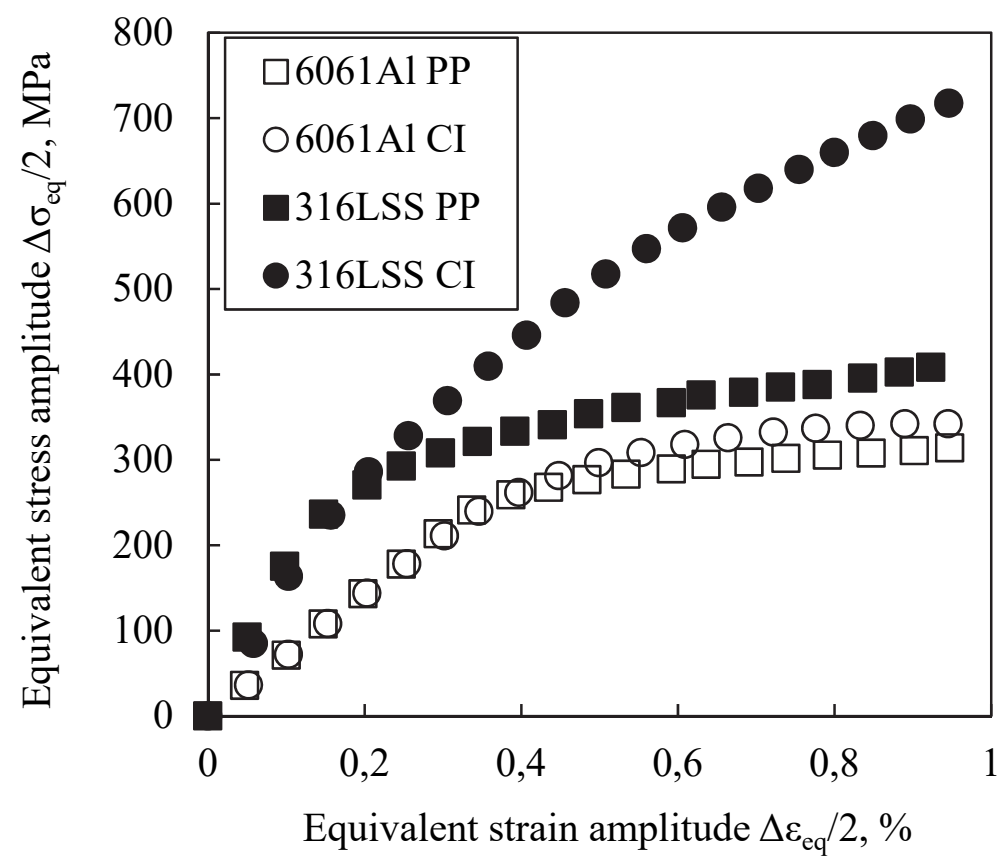

Figure 2: Cyclic curves of $6061 \mathrm{Al}$ and 316LSS.

However, $6061 \mathrm{Al}$ cyclic curves follow approximately the same trend resulting in a slight additional hardening if compared to $316 \mathrm{LSS}$.

Notches and geometrical discontinuities provoke stress concentration effects which must be considered when static and fatigue failure are evaluated. The model developed by Kuhn and Hardraht [18] assumes that fatigue failure occurs if the average stress over a length A from the notch root is equal to the fatigue limit of the smooth specimen. The model have been modified by Neuber assuming that the length A it's a constant depending on the ultimate tensile strength of the material $\sigma_{U}[19]$. The final equation proposed by Neuber is as follows

$$
K_{\mathrm{f}}=1+\frac{\left(K_{\mathrm{t}, \mathrm{n}}-1\right)}{1+\sqrt{\frac{\varrho}{r}}}
$$

The parameter quantifying notch sensitivity is called $\varrho$. High values of $\varrho$ correspond to materials with low notch sensitivity and vice-versa. Therefore, fatigue life is highly or slightly reduced than the quantity indicated by $K_{\mathrm{t}, \mathrm{n}}$, depending on notch sensitivity. The values of notch sensitivity can be obtained easily from tables and take the values of $\varrho=0.6 \mathrm{~mm}$ for $6061 \mathrm{Al}$ and $\varrho=0.3 \mathrm{~mm}$ for 316LSS [49].

\section{Test conditions}

Multiaxial low cycle strain-controlled tests have been conducted on circumferentially notched specimens machined from round bars. The analyzed specimens feature four different values of stress concentration factors referred to the net section $K_{\mathrm{t}, \mathrm{n}}: 1.5,2.5,4.2$ and 6.0 (Fig. 3).

Strain controlled tests have been carried out applying a strain range $\Delta \varepsilon_{\text {eq }} / 2=0.25 \%$ for Al6061 and $\Delta \varepsilon_{\text {eq }} / 2=0.35 \%$ for 316LSS. A Servo hydraulic testing machine which can perform tensile and torsion tests has been employed for the tests. The axial and shear displacements has been measured by an extensometer made by two bars of ceramic material with a gage length of $12 \mathrm{~mm}$. In this study, the strains at the notch root was not taken into account for the determination of the displacement. 


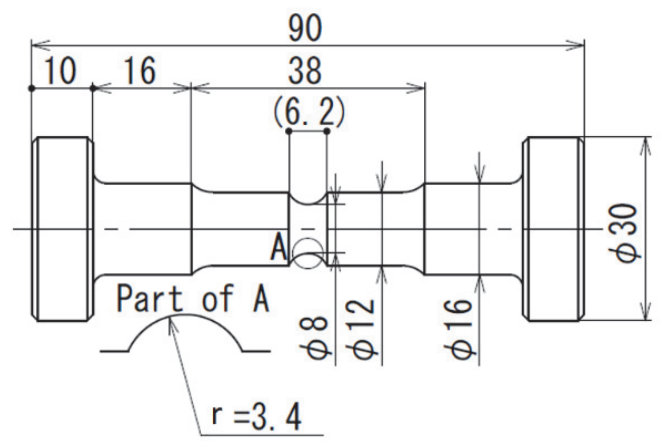

(a) $K_{\mathrm{t}, \mathrm{n}}=1.5$

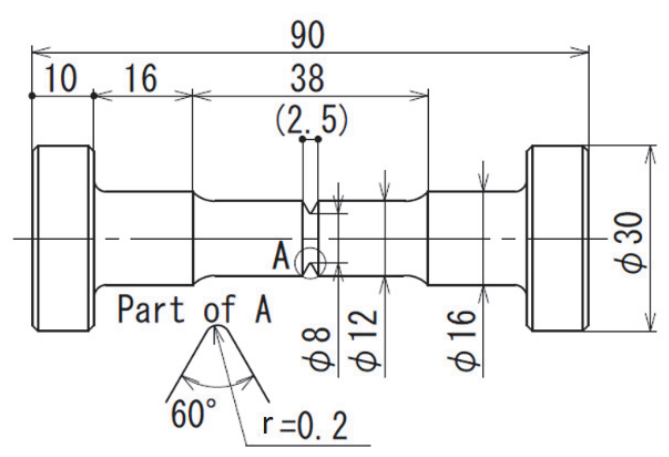

(c) $K_{\mathrm{t}, \mathrm{n}}=4.2$

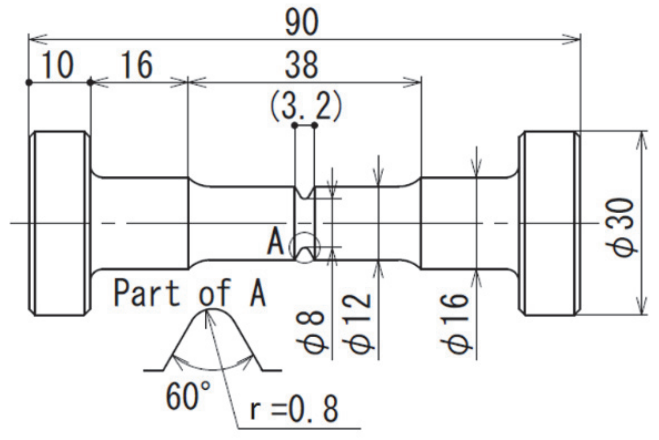

(b) $K_{\mathrm{t}, \mathrm{n}}=2.5$

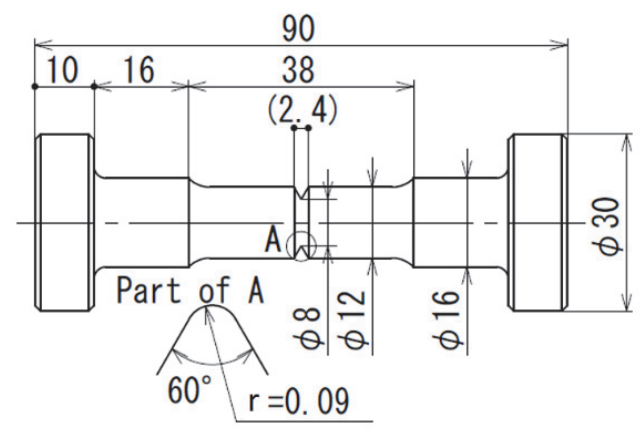

(d) $K_{\mathrm{t}, \mathrm{n}}=6.0$

Figure 3: Tested notched specimens (mm).

\section{TEST RESUlTS}

\section{Failure life}

$\checkmark$ he number of cycles to failure (failure life), $N_{\mathrm{f}}$, for each specimen is listed in Tab. 2. The failure life corresponds to the cycle where the stress amplitude becomes the $3 / 4$ of the maximum stress in a cycle to avoid the complete

1 propagation of the crack and therefore rupture of the specimen.

\begin{tabular}{cccccc}
\hline \multirow{2}{*}{ Loading paths } & & \multicolumn{2}{c}{$6061 \mathrm{Al}$} & \multicolumn{2}{c}{$316 \mathrm{LSS}$} \\
\cline { 4 - 6 } & $K_{\mathrm{t}, \mathrm{n}}$ & $\Delta \varepsilon_{\mathrm{eq}} / 2$ & $N_{\mathrm{f}}$ & $\Delta \varepsilon_{\mathrm{eq}} / 2$ & $N_{\mathrm{f}}$ \\
Cycles & $\%$ & Cycles \\
& 1 & & 44500 & & 6089 \\
\multirow{4}{*}{ PP } & 1.5 & & 3848 & & 2237 \\
& 2.5 & 0.25 & 1267 & 0.35 & 871 \\
& 4.2 & & 788 & & 571 \\
& 6 & & 730 & & 418 \\
\hline \multirow{4}{*}{ CI } & 1 & & 6500 & & 2082 \\
& 1.5 & & 1020 & & 2248 \\
& 2.5 & 0.25 & 298 & 0.35 & 475 \\
& 4.2 & & 207 & & 212 \\
& 6 & & 205 & & 156 \\
\hline
\end{tabular}

Table 2: Test results. 
Non-proportional loading causes a reduction of fatigue life for both steel and aluminum. In detail, additional hardening and activation of multiple slip bands caused by the rotation of principal stress are the phenomena which severely compromise the failure life. The reduction of failure life is also induced by stress concentration effects. The trend of failure life reduction caused by stress concentration effects depends on the material. In case of 6061Al, the discrepancy between the failure life of specimens with $K_{\mathrm{t}, \mathrm{n}}=4.2$ and 6.0 is small both for non-proportional and proportional loading. The failure life of 316LSS is instead sensibly reduced also for high values of $K_{\mathrm{t}, \mathrm{n}}$. Failure life data relative to 316LSS features an anomalous behavior for $K_{\mathrm{t}, \mathrm{n}}$ 1.5. In this case, non-proportional loading does not influence fatigue life as it is equal the proportional case.

\section{Crack analysis}

Crack initiation site was found to be shifted from the notch tip in 316LSS notched specimens analyzed in a previous study [46]. A successive study conducted on those specimens by Gallo et al. [50] from a sophisticated FEM model, evidenced that the shift of the crack initiation site was caused by particular strain gradients. Additional hardening process due to the application of a non-proportional loading path has been detected as the cause of those strain gradients. The maximum value of the distance from the notch tip was found for low stress concentration. Considering crack initiation site through a new stress concentration factor improved the results of fatigue life evaluation. Giving the relevance of the phenomenon in life estimation, aluminum alloy was also analyzed in this study. Specimens with $K_{t, \mathrm{n}}=1.5$ and 2.5 were divided along the axis to detect the crack initiation site. The results of the investigations have been compared with 316LSS. The pictures of the sectioned specimens are shown in Fig. 4 and Fig. 5.

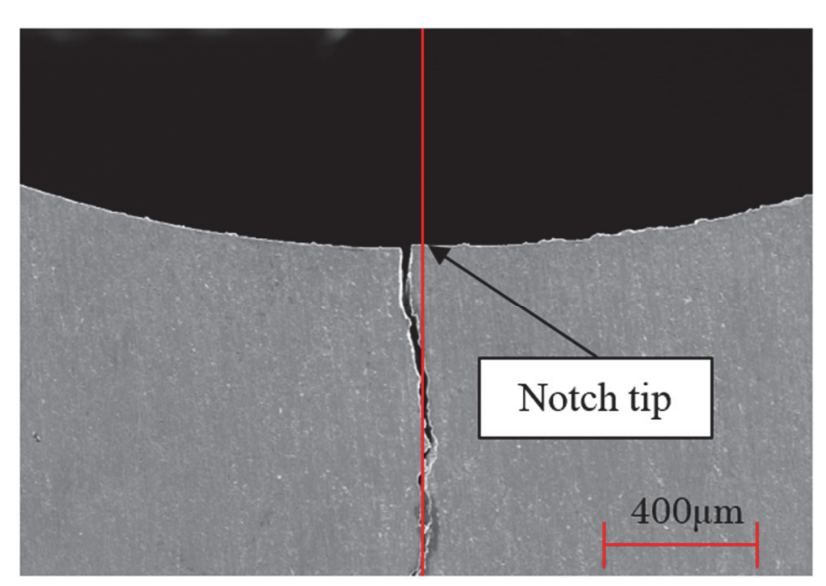

(a) $K_{\mathrm{t}, \mathrm{n}}=1.5$

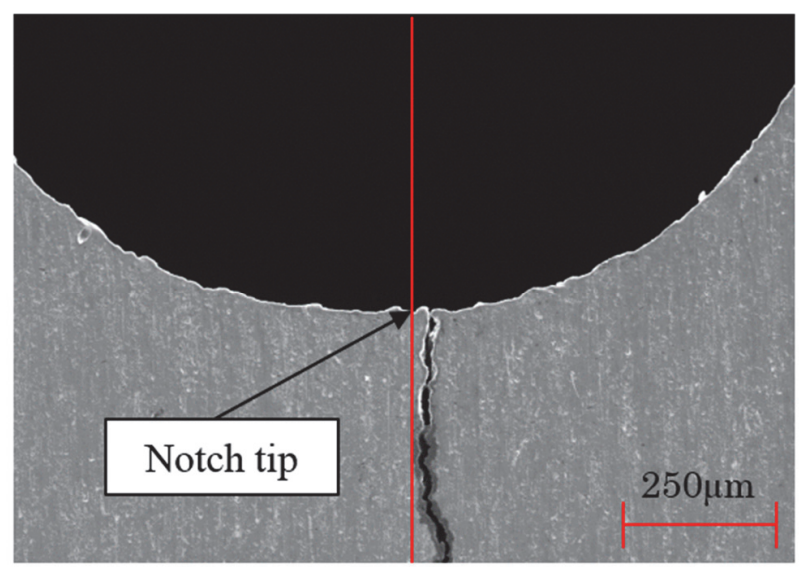

(b) $K_{\mathrm{t}, \mathrm{n}}=2.5$

Figure 4: Crack initiation site on the notch surface for 6061Al.

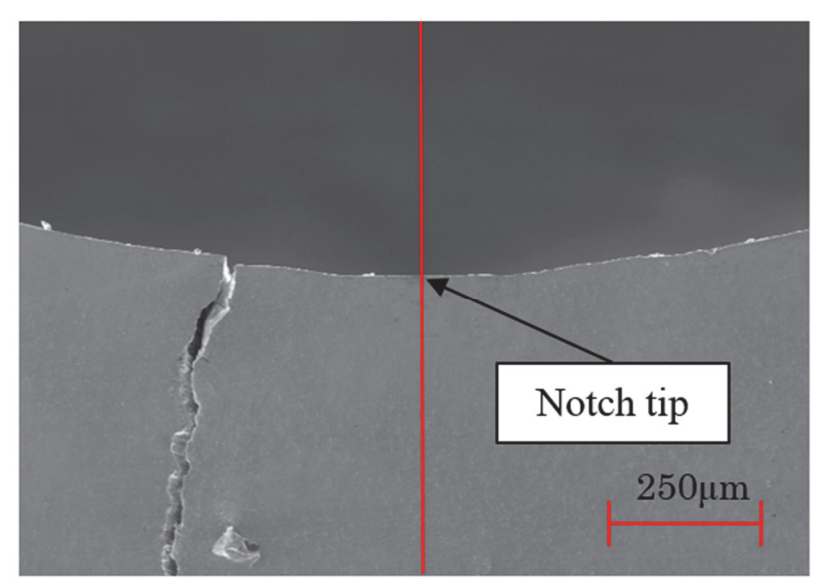

(a) $K_{\mathrm{t}, \mathrm{n}}=1.5$

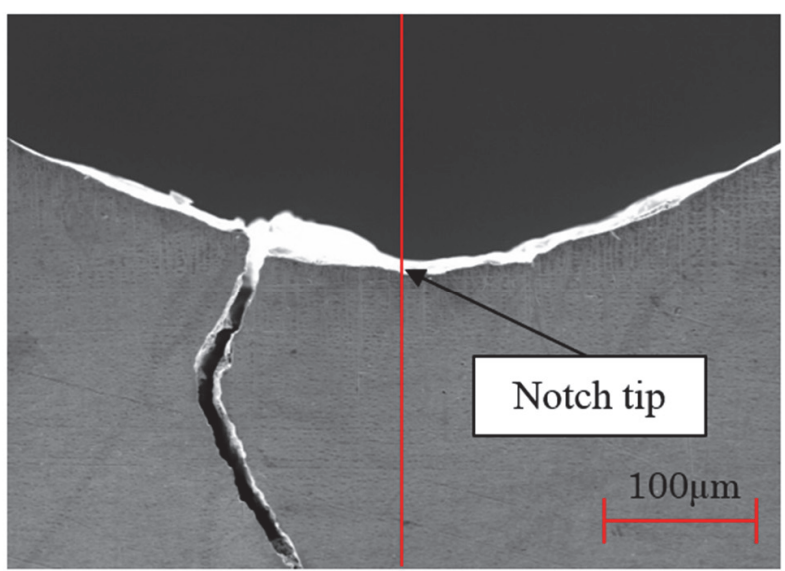

(b) $K_{\mathrm{t}, \mathrm{n}}=2.5$

Figure 5: Crack initiation site on the notch surface for 316LSS. 
Crack initiation site on $6061 \mathrm{Al}$ is located at the notch tip for both $K_{t, \mathrm{n}}=1.5$ and 2.5, proving that materials with low additional hardening do not experience the same phenomenon observed for materials characterized by a high level of additional hardening. For what concerns the specimens with $K_{t, \mathrm{n}}=4.2$ and 6.0, the investigation of the crack initiation site has been avoided both for $6061 \mathrm{Al}$ and 316LSS as failure life can be attributed mostly to crack propagation in case of high stress concentration effects at the notch tip [45].

\section{ITOH-SAKANE PARAMETER}

he presented models for life evaluation are based on the Itoh-Sakane (I-S) parameter [42,43]:
$\Delta \varepsilon_{\mathrm{NP}}=\Delta \varepsilon_{\mathrm{eq}}\left(1+\alpha f_{\mathrm{NP}}\right)$

The method consists in a modification of the equivalent applied strain range. Additional hardening and severity of nonproportional loading path are included through the parameters $\alpha$ and $f_{\mathrm{NP}}$, respectively. In case of 316LSS $\alpha=0.9$, evaluated as the ratio between the increase in stress amplitude in CI to that in PP. The reduction of fatigue life due to non-proportional loading in Al6061 and other materials is not attributed to additional hardening effects [44]. Therefore, the material constant for the evaluation of the reduction of fatigue life $\alpha^{*}$ replaces the additional hardening parameter $\alpha$ in the evaluation of $\Delta \varepsilon_{\mathrm{NP}}$ in case of 6061Al:

$$
\Delta \varepsilon_{\mathrm{NP}}=\Delta \varepsilon_{\mathrm{eq}}\left(1+\alpha^{*} f_{\mathrm{NP}}\right)
$$

$\alpha^{*}$ is defined as the ratio of $N_{\mathrm{f}}$ in CI with $N_{\mathrm{f}}$ in PP at the same applied $\Delta \varepsilon_{\mathrm{eq}}$. The parameter $\alpha^{*}$ can be also accurately evaluated considering an equation correlating the stress $\sigma_{\mathrm{U}}$ and Yield stress $\sigma_{\mathrm{Y} 0.02}$ [44]:

$$
\alpha^{*}=\frac{\left(\sigma_{U}-\sigma_{Y}\right)}{\sigma_{B}}
$$

In the case of A16061 $\alpha^{*}=0.5$ [44]. I-S parameter requires in input the principal (or equivalent in case of circle) strain range, $f_{\mathrm{NP}}$ and $\alpha$, resulting in a parameter simple to obtain compared to the models currently available. In fact, most of them are characterized by the necessity to detect a critical plane and require fatigue parameters such as $\sigma_{\mathrm{f}}^{\prime}$ and $\varepsilon_{\mathrm{f}}^{\prime}[4-6]$. The I-S model however has been proven reliable only for constant amplitude loading path. Furthermore, the model cannot return any information about the crack orientation.

I-S parameter only provides a methodology to modify the strain parameter. Therefore, it becomes necessary to associate the parameter with a model which correlates the parameter to the number of cycles to failure. In a previous work, the result of the application of I-S parameter on notched specimens has been compared with the data of smooth specimen, giving good results. [46,47,50]. However, the design phase requires a model that allows to calculate the number of cycles to failure. Originally, the model has been correlated with the Universal Slope Method (USM) developed by Manson-Coffin [51]. Basic properties obtainable with a tensile test are sufficient to define USM, making it suitable with the concept of simplicity characterizing also I-S parameter.33 In this work, two additional models requiring in input the static mechanical properties of the material have been considered: Muralidharan-Manson (M-M) [52] and Bäumel-Seeger (B-S) [53]. The models are presented in the equations below:

Universal Slope Method (USM):

$$
\Delta \varepsilon=A\left(N_{\mathrm{f}}\right)^{-0.12}+B\left(N_{\mathrm{f}}\right)^{-0.6}
$$

Muralidharan-Manson (M-M):

$$
\Delta \varepsilon=1.17\left(\frac{\sigma_{\mathrm{U}}}{E}\right)^{0.832}\left(N_{\mathrm{f}}\right)^{-0.09}+0.0266 \varepsilon_{\mathrm{U}}^{0.155}\left(\frac{\sigma_{\mathrm{U}}}{E}\right)^{-0.56}\left(N_{\mathrm{f}}\right)^{-0.56}
$$


Bäumel-Seeger (B-S) for aluminum alloy

$$
\frac{\Delta \varepsilon}{2}=1.67 \frac{\sigma_{\mathrm{U}}}{E}\left(2 N_{\mathrm{f}}\right)^{-0.095}+0.35\left(2 N_{\mathrm{f}}\right)^{-0.69}
$$

Bäumel-Seeger (B-S) for steel alloys:

$$
\frac{\Delta \varepsilon}{2}=1.50 \frac{\sigma_{\mathrm{U}}}{E}\left(2 N_{\mathrm{f}}\right)^{-0.087}+0.59 \psi\left(2 N_{\mathrm{f}}\right)^{-0.58}
$$

where,

$$
\begin{aligned}
& \psi=1 \text { if } \frac{\sigma_{U}}{E} \\
& \psi=1.375-125 \frac{\sigma_{U}}{E} \text { if } \frac{\sigma_{U}}{E}<0.003
\end{aligned}
$$

In order to evaluate the appropriate model to employ, fatigue data of smooth specimens under proportional and nonproportional loading have been synthesized with I-S parameter. The result of the correlation with USM, M-M and B-S for both 6061 Al and 316LSS have been represented in Fig. 6 and Fig. 7. I-S parameter associated with B-S model describes accurately the behavior of aluminum. In case of steel, there is no consistent discrepancy between the proposed solutions. Therefore, B-S model has been selected for both materials. The Eq. (11) have been employed for 6061Al and Eq. (12) for 316LSS.

$$
\begin{aligned}
& \frac{\Delta \varepsilon_{\mathrm{NP}}}{2}=1.67 \frac{\sigma_{U}}{\mathrm{E}}\left(2 N_{\mathrm{f}}\right)^{-0.095}+0.35\left(2 N_{\mathrm{f}}\right)^{-0.69} \\
& \frac{\Delta \varepsilon_{\mathrm{NP}}}{2}=1.50 \frac{\sigma_{U}}{\mathrm{E}}\left(2 N_{\mathrm{f}}\right)^{-0.087}+0.59\left(2 N_{\mathrm{f}}\right)^{-0.58}
\end{aligned}
$$

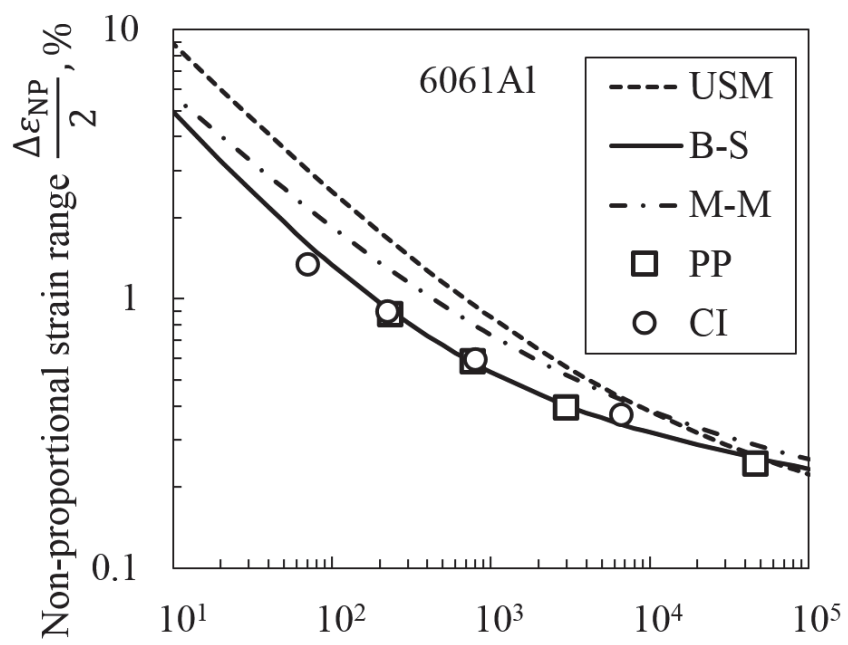

Number of cycles to failure $N_{\mathrm{f}}$, cycles

Figure 6: Crack Correlation of fatigue life of $6061 \mathrm{Al}$ smooth specimens subjected to PP and CI loading paths by using I-S parameter associated with USM, M-M and B-S models. 


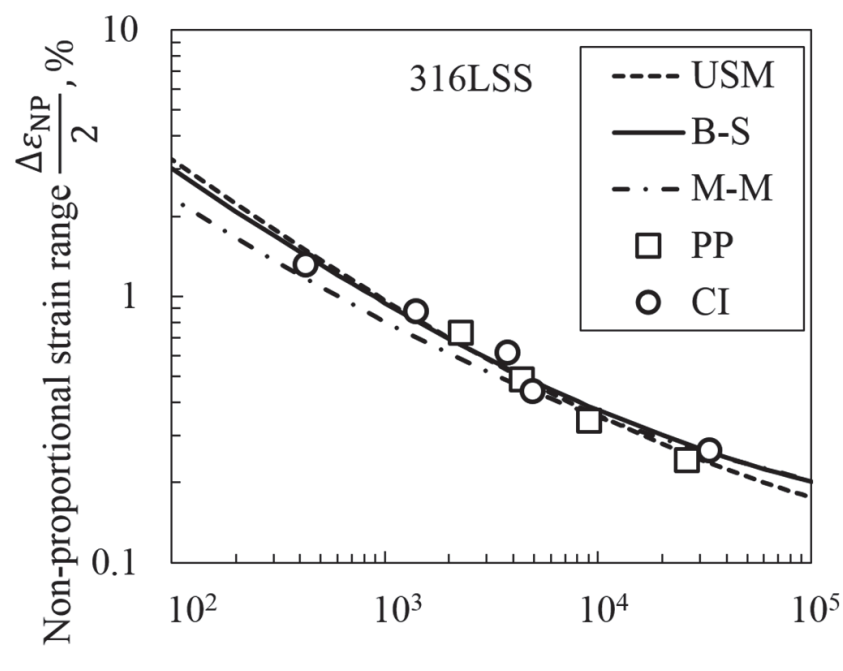

Number of cycles to failure $N_{\mathrm{f}}$, cycles

Figure 7: Correlation of fatigue life of 316LSS smooth specimens subjected to PP and CI loading paths by using I-S parameter associated with USM, M-M and B-S models.

\section{LIFE EVALUATION}

$\mathrm{I}$

$\mathrm{n}$ this chapter, experimental failure life of notched specimen has been correlated with Itoh-Sakane model. The model presented in Eq. (2) has been modified to include the elastic stress concentration factor evaluated in the elastic and static field. For sake of brevity, the counterpart for aluminum modified with $\alpha^{*}$ is not reported.

$$
K_{\mathrm{t}, \mathrm{n}} \Delta \varepsilon_{\mathrm{NP}}=K_{\mathrm{t}, \mathrm{n}} \Delta \varepsilon_{\mathrm{eq}}\left(1+\alpha f_{\mathrm{NP}}\right)
$$

Eq. (13) has been employed only for 316LSS stainless steel notched specimens [46,50]. In these studies, the results for notched specimens has been compared with data of smooth specimens. This equation is assuming that $K_{\varepsilon} \approx K_{\mathrm{t}, \mathrm{n}}$ because an assessment of $K_{\varepsilon}$ in elastic plastic regime would require complicate procedure such as finite element analysis accounting of cyclic stress-strain relationships depending on strain path, material and $K_{\mathrm{t}, \mathrm{n}}$ under non-proportional LCF. According to Eq. (13), the left term of Eq. (11) and (12) were multiplied by $K_{\mathrm{t}, \mathrm{n}}$ resulting in Eq. (14) for 6061 Al and (15) for 316LSS.

$$
\begin{aligned}
& \frac{K_{\mathrm{t}, \mathrm{n}} \Delta \varepsilon_{\mathrm{NP}}}{2}=1.67 \frac{\sigma_{\mathrm{U}}}{E}\left(2 N_{\mathrm{f}}\right)^{-0.095}+0.35\left(2 N_{\mathrm{f}}\right)^{-0.69} \\
& \frac{K_{\mathrm{t}, \mathrm{n}} \Delta \varepsilon_{\mathrm{NP}}}{2}=1.50 \frac{\sigma_{\mathrm{U}}}{E}\left(2 N_{\mathrm{f}}\right)^{-0.087}+0.59\left(2 N_{\mathrm{f}}\right)^{-0.58}
\end{aligned}
$$

The results of the application of Eq. (14) and Eq. (15) for life evaluation are shown in Fig. 8 and Fig. 9. 6061Al data are underestimated for $K_{\mathrm{t}, \mathrm{n}} 4.2$ and 6. Data of 316LSS is generally well estimated, with the majority of the results located in the upper portion of the scatter band.

Successively, the elastic stress concentration factor has been replaced by the fatigue notch factor defined in Eq. (1) which takes into account the material notch sensitivity. $K_{\mathrm{f}}$ has been applied under the hypothesis that $K_{\mathrm{f}}$ does not depend on the loading path and material cyclic plastic behavior.

$$
\frac{K_{\mathrm{f}} \Delta \varepsilon_{\mathrm{NP}}}{2}=1.67 \frac{\sigma_{\mathrm{U}}}{E}\left(2 N_{\mathrm{f}}\right)^{-0.095}+0.35\left(2 N_{\mathrm{f}}\right)^{-0.69}
$$




$$
\frac{K_{\mathrm{f}} \Delta \varepsilon_{\mathrm{NP}}}{2}=1.50 \frac{\sigma_{\mathrm{U}}}{E}\left(2 N_{\mathrm{f}}\right)^{-0.087}+0.59\left(2 N_{\mathrm{f}}\right)^{-0.58}
$$

The results of the application of $K_{\mathrm{f}}$ on I-S model are shown in Fig. 10 and Fig. 11.

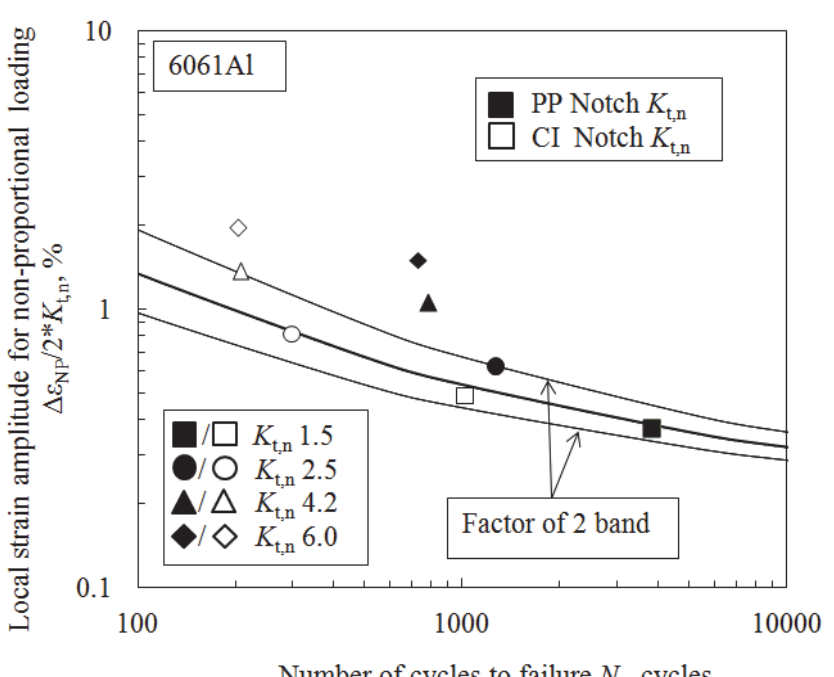

Figure 8: Life evaluation of 6061Al employing I-S parameter modified with $K_{\mathrm{t}, \mathrm{n}}$.

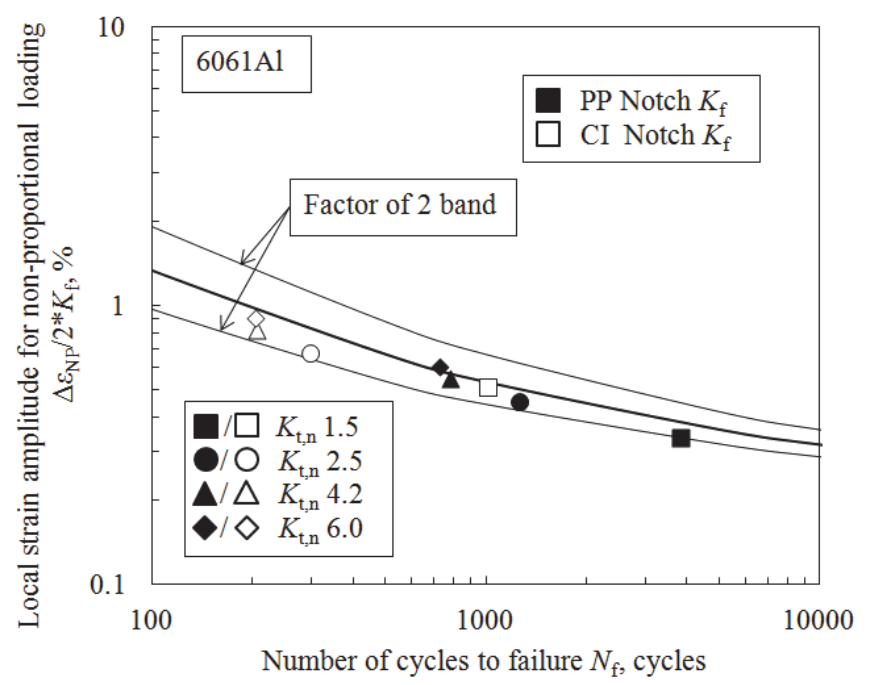

Figure 10: Life evaluation of $6061 \mathrm{Al}$ employing I-S parameter modified with $K_{\mathrm{f}}$.

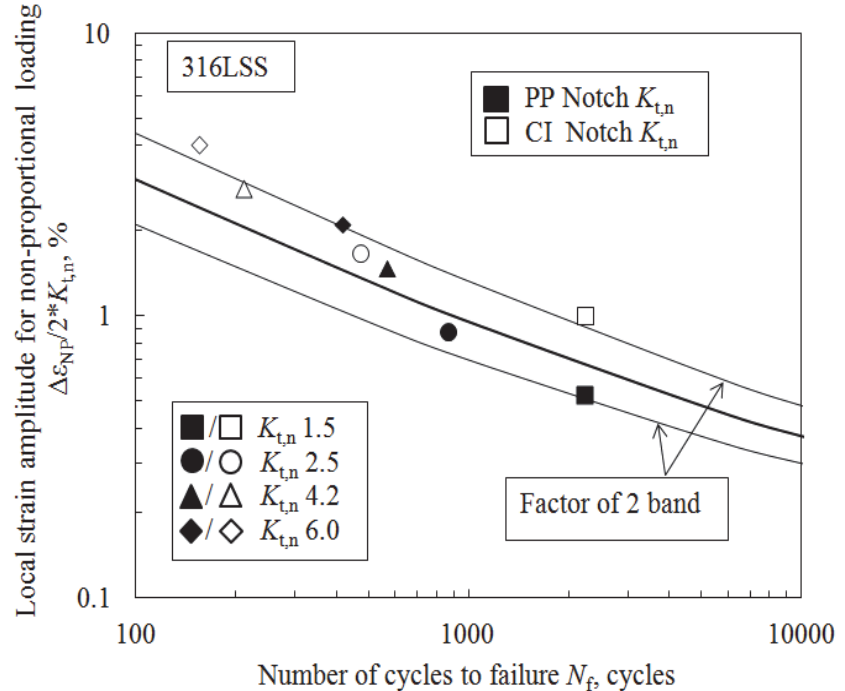

Figure 9: Life evaluation of 316LSS employing I-S parameter modified with $K_{\mathrm{t}, \mathrm{n}}$.

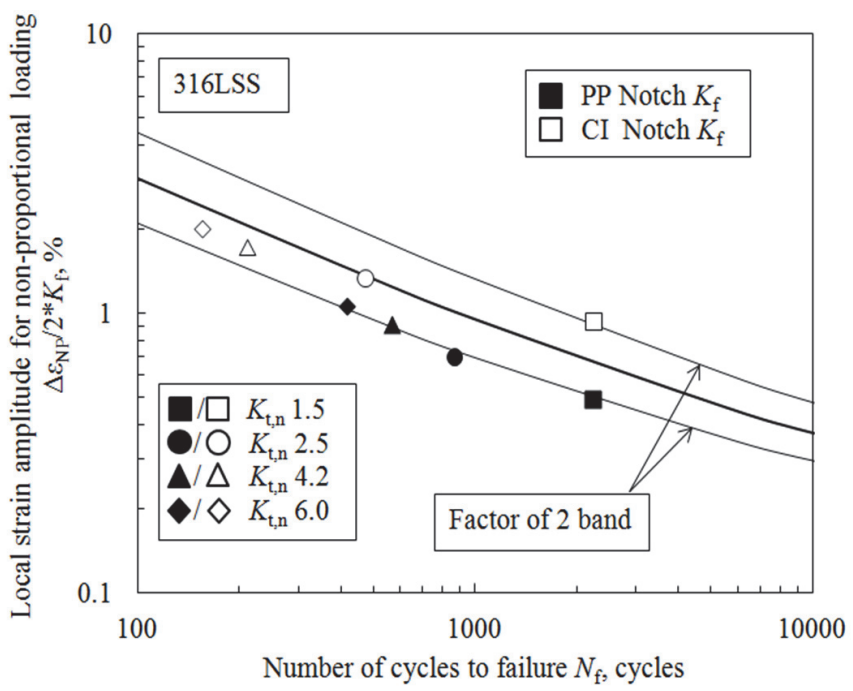

Figure 11: Life evaluation of 316LSS employing I-S parameter modified with $K_{\mathrm{f}}$.

The results related to high values of $K_{\mathrm{t}, \mathrm{n}}$ are sensibly improved for $6061 \mathrm{Al}$. Failure life data are well correlated in the factor of 2 band. In case of 316LSS, there is a general overestimation of failure life in the case of PP loading. Non-proportional loading data are well correlated except for $K_{\mathrm{t}, \mathrm{n}}=1.5$. Crack initiation site has been also taken into account in life evaluation. As described in the section 3.2, the cases where crack initiation site has been detected away from the notch tip are limited. Specifically, the influence of this phenomenon on life evaluation has been considered only for the 316LSS specimens with $K_{\mathrm{t}, \mathrm{n}}=1.5$ and 2.5. In order to take into account the crack initiation site, a FEM analysis has been conducted on the considered specimens. The same stress recorded in the experimental tests conducted on the notched specimens has been applied as a tensile stress of a static linear analysis. The local stress occurring at the same location where the crack initiated $\sigma^{\prime}$ loc has been obtained. The distance of the crack initiation spot from the tip has been obtained by observing the fracture on the tested specimens. A new stress concentration factor $K_{\mathrm{t}}^{\prime}$ has been evaluated as the ratio between the local value of stress and the nominal stress $\sigma_{\mathrm{N}}$ already defined [39]. 


$$
K_{\mathrm{f}}^{\prime}=\frac{\sigma_{\mathrm{loc}}^{\prime}}{\sigma_{N}}
$$

The final stress concentration for $K_{\mathrm{t}, \mathrm{n}}=1.5$ and 2.5 of 316LSS specimens which takes into account the notch sensitivity and the crack initiation site has been calculated as:

$$
K_{\mathrm{f}}^{\prime}=1+\frac{\left(K_{\mathrm{t}}^{\prime}-1\right)}{1+\sqrt{\frac{\varrho}{r}}}
$$

Fatigue life has been finally evaluated with the model obtained by substituting the stress concentration of Eq. (17) into Eq. (13). The results are represented in Fig. 12. Considering crack initiation position slightly improves the results.

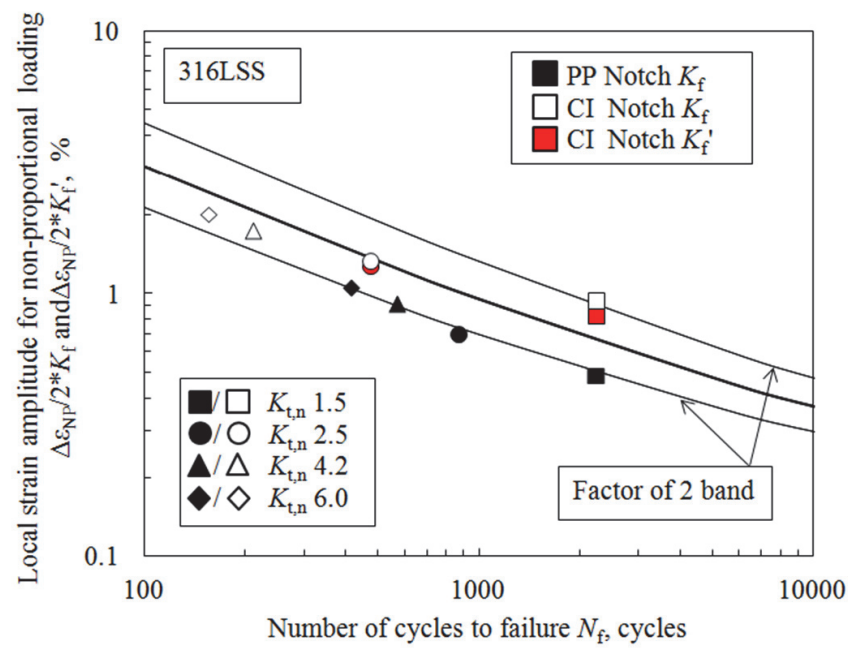

Figure 12: Life evaluation of 316LSS employing I-S parameter modified with $K_{\mathrm{f}}$.

\section{Discussion}

T

he accuracy of the evaluation of failure life employing Itoh-Sakane's parameter modified with $K_{\mathrm{t}, \mathrm{n}}$ varies depending on the considered material and notch radius. Fig. 8 shows that proportional and non-proportional data of $6061 \mathrm{Al}$ are characterized by the same trend. Failure lives of specimens featuring high values of $K_{\mathrm{t}, \mathrm{n}}(4.2$ and 6.0$)$ are underestimated, while data associated with $K_{\mathrm{t}, \mathrm{n}}=1.5$ and 2.5 are located within the factor of 2 band. The underestimation is due to the low notch sensitivity. In fact, Tab. 2 shows that despite of the increment of stress concentration factor from 4.2 to 6.0, failure life does not decrease as suggested by the values of $K_{\mathrm{t}, \mathrm{n}}$. Therefore, if the parameter is modified considering the stress concentration factor evaluated in the static field, the underestimation is unavoidable. In case of 316LSS, the trend of the data is slightly different from 6061 Al. Failure life of the specimens subjected to PP is well evaluated. CI case features a slight underestimation for $K_{\mathrm{t}, \mathrm{n}}=6.0$ and 1.5. Generally, fatigue life of steel specimens is estimated more accurately than $6061 \mathrm{Al}$ both for proportional and non-proportional loading, due to the higher notch sensitivity of the material.

In order to take into account the material notch sensitivity, fatigue notch factor $K_{\mathrm{f}}$ calculated by means of Eq. (1) has been considered in I-S parameter. Failure life data of $6061 \mathrm{Al}$ evaluated by using the model modified with $K_{\mathrm{f}}$ are located within the factor of 2 scatter band (Fig. 11), suggesting that the cause of the underestimation is notch sensitivity. In case of 316LSS, the improvement does not extend for all data. If non-proportional loading is considered, failure life is well estimated for $K_{\mathrm{t}, \mathrm{n}}$ =2.5, 4.2 and 6.0. However, it can be observed in Fig. 12 that the data related to PP for 316LSS are overestimated, probably due to the hypothesis $K \varepsilon \approx K_{\mathrm{t} . n}$. , but still in the limit of the factor of 2 band.

Finally, there is an anomalous case for what concerns life evaluation of 316LSS. Failure life of the specimen featuring $K_{\mathrm{t}, \mathrm{n}}=1.5$ is underestimated despite of the application of $K_{\mathrm{f}}$, indicating that the cause of the underestimation is not notch 
sensitivity. Therefore, crack initiation site has been considered in failure life evaluation. As mentioned above, crack initiation site is not located at the notch tip especially for low values of $K_{\mathrm{t}, \mathrm{n}}$ and materials characterized by a high level of additional hardening. Among the specimens and test conditions analyzed in this work, 316LSS specimen with $K_{\mathrm{t}, \mathrm{n}}=1.5$ matches the conditions above mentioned. This combination of notch radius and material returned an anomalous result as evidenced in Tab. 2. Stress concentration factors $K_{\mathrm{t}, \mathrm{n}}$ and $K_{\mathrm{f}}$ both consider the crack initiating at the notch tip. However, if crack initiation site is located in a spot moved from the notch tip fatigue life is underestimated. The results are slightly improved as shown in Fig. 12. The result for $K_{\mathrm{t}, \mathrm{n}}=2.5$ does not present a significant improvement, suggesting that the influence of the crack initiation site is limited to low values of $K_{\mathrm{t}, \mathrm{n}}$. The final models are presented in Eq. (18) for aluminum and Eq. (19) for 316LSS:

$$
\begin{aligned}
& \frac{K_{\mathrm{f}} \Delta \varepsilon_{\mathrm{NP}}}{2}=1.67 \frac{\sigma_{\mathrm{U}}}{E}\left(2 N_{\mathrm{f}}\right)^{-0.095}+0.35\left(2 N_{\mathrm{f}}\right)^{-0.69} \\
& \frac{K_{\mathrm{f}}^{\prime} \Delta \varepsilon_{\mathrm{NP}}}{2}=1.50 \frac{\sigma_{\mathrm{U}}}{E}\left(2 N_{\mathrm{f}}\right)^{-0.087}+0.59\left(2 N_{\mathrm{f}}\right)^{-0.58}
\end{aligned}
$$

Note that in case of aluminum $K_{\mathrm{f}}$ has been applied instead of $K_{\mathrm{f}}$ since crack initiation position does not have influence on fatigue life. Eq. (20) and Eq. (21) take into account the geometry of the specimens, notch sensitivity and crack initiation site (for the cases where the phenomenon is relevant) in fatigue life evaluation of notched specimens subjected to proportional and non-proportional multiaxial low cycle fatigue. The model is not intended to be a replacement of the critical plane models but an alternative that simplify the life evaluation, making this model suitable for preliminary evaluations which would be demanding in terms of time in order to take into account all the phenomena involved for this typology of loading and geometry.

Some last considerations about the model must be made. Being the crack initiation site on a notch for non-proportional loading a phenomenon rarely reported in the literature, its evaluation a priori still relies on the experimental observations of the crack.

\section{CONCLUSIONS}

I n order to observe the influence of notch sensitivity and crack initiation site on failure life, notched specimens made by 316LSS and aluminum 6061 Al were tested with proportional and non-proportional low cycle fatigue loading paths. Failure life was obtained, evidencing a general reduction in fatigue life for non-proportional loading with exceptions for aluminum $K_{\mathrm{t}, \mathrm{n}}=4.2$ and 6 and steel $K_{\mathrm{t}, \mathrm{n}}=1.5$. Crack initiation site was also observed. Failure life was evaluated by means of I-S parameter associated with B-S model. The model was then modified by applying the stress concentration factor evaluated in the elastic field returning a general underestimation of fatigue life especially for aluminum specimens with $K_{\mathrm{t}, \mathrm{n}}=4.2$ and 6.0. The model was successively modified by taking into account the notch sensitivity and also the crack initiation position in the case of steel. The modified model returned generally good results, verifying the accuracy of the methodology proposed in this paper. The conclusions that can be drawn from the present work are listed below.

(1) The crack initiation site on the notch surface depends on notch radius and additional hardening and influences the number of cycles to failure.

(2) Notch sensitivity has influence on the failure life in equal measure for proportional and non-proportional loading.

(3) I-S parameter associated with the B-S model can be obtained from the static properties and the cyclic curves of the material and returns sound results in terms of failure life evaluation.

(4) I-S parameter modified with $K_{\mathrm{f}}$ and $K_{\mathrm{f}}^{\prime}$ allows to consider the notch sensitivity of the material and the crack initiation site.

\section{REFERENCES}

[1] Gough, H.J. Pollard, H.V. (1935). The strength of metals under combined alternating stresses, Proceedings of the Institute of Mechanical Engineers, 131, pp. 3-103. DOI:10.1243/PIME_PROC_1935_131_008_02.

[2] Sines, G. (1955). Fatigue of materials under combined repeated stresses with superimposed static stresses, Tech. Note 3495, National Advisory Committee of Aeronautic, Washington DC. 
[3] Findley, W.N. (1959). A theory for the effect of mean stress on fatigue of metals under combined torsion and axial loading or bending, Journal of Engineering for Industry, pp. 301-306.

[4] Brown, M.W. and Miller, K.J., (1978), A theory for fatigue under multiaxial stress-strain conditions, Proceedings of the Institute of Mechanical Engineers, 187, pp. 745-756. DOI: 10.1243/PIME_PROC_1973_187_069_02.

[5] Fatemi, A. and Socie, D.F. (1988). A critical plane approach to multiaxial fatigue including out-of-phase loading, Fatigue and Fracture of Engineering Materials and Structures, 11, pp. 149-166.

DOI:10.1111/j.1460-2695.1988.tb01169.x.

[6] Smith, R.N., Watson, P., Topper, T.H. (1970). A stress-strain function for the fatigue of metals, Journal of Materials, 5(4), pp. 767-778.

[7] Liu, K.C. (1993). A method based on virtual strain-energy parameters for multiaxial fatigue life prediction, Advances in Multiaxial Fatigue, D.L. McDowell and R. Ellis eds., ASTM STP 1191, American Society for Testing and Materials, West Conshohocken, PA, pp. 37-54.

[8] Kanazawa, K., Miller, K.J., Brown, M.W. (1979). Cyclic deformation of 1\%Cr-Mo-V steel under out-of-phase loads, Fatigue and Fracture of Engineering Materials and Structures, 2(3), pp. 217-228.

DOI: $10.1111 /$ j.1460-2695.1979.tb01357.x.

[9] McDowell, F.L. (1983). On the path dependence of transient hardening and softening to stable states under complex biaxial cyclic loading, in: Desai, Gallagher (Eds.), Proceedings of the International Conference on Constitutive Laws for Engineering Materials, pp. 125-135.

[10] Krempl, E. and Lu, H. (1983). Comparison of the stress response of an aluminum alloy tube to proportional and alternate axial and shear strain paths at room temperature, Mechanics of Materials, 2(3), pp. 183-192.

[11] Nitta, A., Ogata, T., Kuwabara, K. (1987). The effect of axial-torsional straining phase on elevated-temperature biaxial low-cycle fatigue life in SUS304 stainless steel, Journal of the Society of Materials Science, Japan, 36(403), pp. 376-382.

[12] Doong, S.H., Socie, D.F., Robertson, I.M. (1987), Dislocation substructures and nonproportional hardening, Transactions of the American Society of Mechanical Engineers - Journal of Engineering Materials and Technology, 112(4), pp. 456-465.

[13] Doong, S.H. and Socie, D.F. (1991). Constitutive modeling of metals under non-proportional cyclic loading Transactions of the American Society of Mechanical Engineers - Journal of Engineering Materials and Technology, 113(1), pp. 23-30.

[14] Itoh, T., Sakane, M., Ohnami, M., Ameyama, K. (1992). Effect of stacking fault energy on cyclic constitutive relation under nonproportional loading, Journal of the Society of Materials Science, Japan, 41(468), pp. 1361-1367.

[15] Chen, X., Gao, Q., Sun, X.F. (1996). Low-cycle fatigue under non-proportional loading, Fatigue and Fracture of Engineering Materials and Structures, 19(7), pp. 839-854.

[16] Shamsaei, N., Gladskyi, M., Panasovskyi, M., Shukaev, S., Fatemi, A. (2010). Multiaxial fatigue of titanium including step loading and load path alteration and sequence effects, International Journal of Fatigue, 32(11), pp. 1862-1874.

[17] Itoh, T, and Yang, T. (2011). Material dependence of multiaxial low cycle fatigue lives under non-proportional loading, International Journal of Fatigue, 33(8), pp. 1025-1031.

[18] Kuhn, P. and Hardraht, H.F. (1952). An engineering method for estimating the notch-size effect in fatigue tests on steel, NACA TN2805, Langley aeronautical laboratory, Washington.

[19] Neuber, H. (1961). Theory of stress concentration for shear-strained prismatic bodies with arbitrary nonlinear stress-strain low, ASME Journal of Applied Mechanics, 28, pp. 544-550.

[20] Nie, H. And Wu, F. (1988). Acta Aeronaut. Astronaut. Sin.,9, A424.

[21] Hoffman, M. and Seeger, T. (1986). Proc. Int. Conf. on Fatigue of Engineering Materials and Structures, London, 1, pp. 195-202.

[22] Peterson, R.E. (1959). Metal Fatigue, McGraw-Hill, New York, pp. 293-306.

[23] Frost, N.E., Marsh, K.J., Pook, L.P. (1974). Metal Fatigue, Oxford University Press.

[24] Molski, K. and Glinka, G. (1981). A method of elastic-plastic stress and strain calculation at a notch root, Materials and Science Engineering, 50, pp. 93-100. DOI: 10.1016/0025-5416(81)90089-6.

[25] Barkey, M.E., Socie, D.F., Hsia, K.J. (1994). A yield surface approach to the estimation of notch strains for proportional and nonproportional cyclic loading, Journal of Engineering Materials and Technology, 116(2), pp. 173-180. DOI:10.1115/1.2904269.

[26] Buczynski, A. and Glinka, G. (2003). An analysis of elasto-plastic strains and stresses in notched bodies subjected to cyclic non-proportional loading paths, European Structural Integrity Society, 31, pp.265-283.

DOI:10.1016/S1566-1369(03)80015-8. 
[27] Ince, A., Glinka, G., Buczynski, A. (2014). Computational modeling of multiaxial elasto-plastic stress-strain response for notched components under non-proportional loading, International Journal of Fatigue, 62, pp. 42-52. DOI: $10.1016 /$ j.ijfatigue.2013.10.008.

[28] Topper, T.H., Wetzel, R.M., Morrow, J. (1969). Neuber's rule applied to fatigue of notched specimens, Journal of Materials, 4, pp. 200-209.

[29] Berto, F. and Lazzarin, P. (2009). A review of the volume-based strain energy density approach applied to Vnotches and welded structures, Theoretical and Applied Fracture Mechanics, 52(3), pp. 183-194.

DOI: $10.1016 / j . t a f m e c .2009 .10 .001$.

[30] Gallo, P., Berto. F., Glinka, G. (2016). Generalized approach to estimation of strains and stresses at blunt V-notches under non-localized creep, Fatigue and Fracture of Engineering Materials and Structures, 39(3), pp. 292-306. DOI: $10.1111 /$ ffe. 12374 .

[31] Gallo. P., Sumigawa, T., Kitamura, T., Berto, F. (2016). Evaluation of the strain energy density control volume for a nanoscale singular stress field, Fatigue and Fracture of Engineering Materials and Structures, 39(12), pp. 15571564. DOI: $10.1111 /$ ffe.12468.

[32] Gallo, P., Sumigawa, T., Kitamura T., Berto, F. (2018). Static assessment of nanoscale notched silicon beams using the averaged strain energy density method, Theoretical and Applied Fracture Mechanics, 95, pp. 261-269. DOI: $10.1016 /$ j.tafmec.2018.03.007.

[33] Meneghetti, G., Campagnolo, A., Berto, F., Tanaka, K. (2018). Notched Ti-6Al-4V titanium bars under multiaxial fatigue: Synthesis of crack initiation life based on the averaged strain energy density, Theoretical and Applied Fracture Mechanics, 96, pp. 509-533. DOI: 10.1016/j.tafmec.2018.06.010.

[34] Campagnolo, A., Meneghetti, G., Berto, F., Tanaka, K. (2017). Crack initiation life in notched steel bars under torsional fatigue: Synthesis based on the averaged strain energy density approach, International Journal of Fatigue, 100, pp. 563-574. DOI: 10.3221/IGF-ESIS.41.02.

[35] Berto, F., Campagnolo, A., Lazzarin, P. (2015). Fatigue strength of severely notched specimens made of Ti-6Al-4V under multiaxial loading, Fatigue and Fracture of Engineering Materials and Structures, 38(5), pp. 503-517. DOI: $10.1111 /$ ffe.12272.

[36] Berto, F., Lazzarin, P., Yates, J.R. (2011). Multiaxial fatigue of V-notched steel specimens: A non-conventional application of the local energy method, Fatigue and Fracture of Engineering Materials and Structures, 34(11), pp. 921-943. DOI: 10.1111/j.1460-2695.2011.01585.x.

[37] Berto, F. and Lazzarin. P. (2011). Fatigue strength of structural components under multi-axial loading in terms of local energy density averaged on a control volume, International Journal of Fatigue, 33(8), pp. 1055-1065.

DOI: $10.1016 /$ j.ijfatigue.2010.11.019.

[38] Tripton, S.M. and Nelson, D.V. (1997). Advances in multiaxial fatigue life prediction for components with stress concentrations, International Journal of Fatigue, 19, pp. 503-515. DOI: 10.1016/S0142-1123(96)00070-9.

[39] Gates, N., Fatemi, A. (2016). Notch deformation and stress gradient effects in multiaxial fatigue, Theoretical and Applied Fracture Mechanics, 84, pp. 3-25. DOI: 10.1016/j.tafmec.2016.02.005.

[40] Atzori, B., Berto, F., Lazzarin, P., Quaresimin, M. (2011). Multi-axial fatigue behaviour of a severely notched carbon steel, International Journal of Fatigue, 28(5-6), pp. 485-493. DOI: 10.1016/j.ijfatigue.2005.05.010.

[41] Carpinteri, A., Spagnoli, A., Vantadori, S. (2009). Multiaxial fatigue life estimation in welded joints using the critical plane approach, International Journal of Fatigue, 31(1), pp. 188-196. DOI: 10.1016/j.ijfatigue.2008.03.024.

[42] Itoh, T., Sakane, M., Ohnami., D.F., Socie, D.F. (1995). Nonproportional low cycle fatigue criterion for Type 304 stainless steel, Journal of Engineering Materials and Technology, 117(3), pp. 285-292. DOI: 10.1115/1.2804541.

[43] Itoh, T., Nakata, T., Sakane, M., Ohnami., M. (1999). Nonproportional low cycle fatigue of 6061 aluminum alloy under 14 strain paths, European Structural Integrity Society, 25, pp. 41-54.

DOI: $10.1016 /$ S1566-1369(99)80006-5.

[44] Itoh, T. and Yang, T. (2011). Material dependence of multiaxial low cycle fatigue lives under non-proportional loading, International Journal of Fatigue, 33, pp. 1025-1031. DOI: 10.1016/j.ijfatigue.2010.12.001.

[45] Sakane, M., Itoh, T., Susaki, T., Kawazoe, Y. (2004). T. Life prediction for notched components in nonproportional low cycle fatigue: experiment and FEM analysis, Pressure Vessel and Piping Codes and Standards, ASME. pp. 31 38. DOI:10.1115/PVP2004-2670.

[46] Itoh, T., Chen, W., Yamamoto, R. Multiaxial low cycle fatigue life of notched specimen for Type 316L stainless steel under non-proportional loading, Journal of Solid Mechanics and Materials Engineering, 5, pp. $230-241$. DOI:10.1299/jmmp.5.230. 
[47] Morishita, T. and Itoh, T. (2016). Evaluation of multiaxial low cycle fatigue life for Type 316L stainless steel notched specimen under non-proportional loading, Theoretical and Applied Fracture Mechanics, 84, pp. 98-105. DOI:10.1016/j.tafmec.2016.02.007.

[48] Suresh, S. (1991). Fatigue of Materials, Cambridge University Press, England.

[49] Sines, G., Waisman, J.L. (Eds). (1969). Metal Fatigue, McGraw-Hill, New York.

[50] Gallo, P., Bressan, S., Morishita, T., Itoh, T., Berto, F. (2017). Analysis of multiaxial low cycle fatigue of notched specimens for type 316L stainless steel under non-proportional loading, Theoretical and Applied Fracture Mechanics, 89, pp. 79-89. DOI: 10.1016/j.tafmec.2017.01.009.

[51] Manson, S.S. (1965). Fatigue - a complex subject - some simple approximations, Experimental Mechanics, 5(7), pp. 193-226. DOI: $10.1007 /$ BF02321056.

[52] Muralidharan, U. and Manson, S.S. (1988). A modified universal slopes equation for estimation of fatigue characteristics of metals, Journal of Engineering Materials and Technology, 110(1), pp. 55-58.

DOI: $10.1115 / 1.3226010$

[53] Bäumel Jr., A. and Seeger, T. (1990). Materials Data for Cyclic Loading, Elsevier Science Publishers, Amsterdam, (supplement 1).

\section{NOMENCLATURE}

$\alpha \quad$ additional hardening coefficient

$\varepsilon_{f}^{\prime} \quad$ fatigue ductility coefficient

$\Delta \varepsilon_{\text {eq }} \quad$ strain range based on von Mises

$\Delta \varepsilon_{\mathrm{NP}} \quad$ non-proportional strain range

$\Delta \sigma_{\mathrm{eq}} \quad$ stress range based on von Mises

$\varepsilon_{U} \quad$ ultimate tensile strain

@ notch sensitivity factor

$\sigma_{f}^{\prime} \quad$ fatigue strength coefficient

$\sigma_{\mathrm{U}} \quad$ ultimate tensile strength

$\sigma_{Y 0.2}$ yield stress at $\varepsilon=0.02 \%$

$A$, $B \quad$ Universal Slope Method coefficients

E Young's modulus

太 $\mathrm{NP} \quad$ non-proportional factor

$K_{\mathrm{t}, \mathrm{n}} \quad$ elastic stress concentration factors referred to the net section

$K_{\mathrm{f}} \quad$ fatigue stress concentration factor

$K_{\mathrm{t}}^{\prime} \quad$ local stress concentration factor

$K_{\mathrm{f}}^{\prime} \quad$ total fatigue stress concentration factor

$N_{\mathrm{f}} \quad$ number of cycles to failure

$r \quad$ notch radius

\section{AbBreviations}

$6061 \mathrm{Al}$ Aluminum Alloy 6061

316LSS Stainless steel AISI 316 L

PP Push-pull strain path

CI Circle strain path

USM Universal slope method

M-M Muralidharan-Manson method

B-S Bäumel-Seeger method 